\title{
Connecting Inquiry, Research, and Technology: The Multigenre Digital Inquiry Project
}

\author{
Marla K. Robertson ${ }^{1, *}$, Amy Piotrowski ${ }^{1} \&$ Jennifer M. Smith ${ }^{2}$ \\ ${ }^{1}$ Utah State University, USA \\ ${ }^{2}$ Texas Christian University, USA \\ *Correspondence: Utah State University, USA. E-mail: mkrobertson2009@gmail.com
}

Received: September 10, 2021

Accepted: Janaury 22, 2022 Online Published: February 10, 2022

doi:10.5430/jct.v11n2p99

URL: https://doi.org/10.5430/jct.v11n2p99

\begin{abstract}
This article describes research on a Multigenre Digital Inquiry Project (MDIP), a technology-infused project designed to provide an opportunity for students to inquire about a topic of interest and share their research using $21^{\text {st }}$ century technologies. Instead of composing a research paper or literature review, students designed a website with pieces written in multiple genres to share their learning, including at least two pieces created using digital tools. In this article, the authors share the design of the MDIP and how it was implemented in three teacher education courses. Data analysis aimed to understand how pre-service teachers engaged in this project and reflected on their learning. Using themes from the analysis of students' end-of-semester reflections and memos written about the pieces included in the projects, the authors share how students valued support in various areas including technology, how they expanded their views of writing and genre, and how their experiences illustrated academic, personal, and pedagogical growth. Ultimately, students learned from this challenging, yet rewarding experience. Finally, the authors share suggestions for others interested in incorporating a MDIP in their work.
\end{abstract}

Keywords: literacy, technology, inquiry, multigenre, genre, preservice, projects, composing

\section{Introduction}

I was so eager to create different pieces for my Weebly [website] that I was excited to wake up early on Saturdays and sit with my coffee to do homework and I don't know the last time that happened. I found so much joy in being creative and thinking critically about the information I wanted to present...This inspired me to one day use this same method of different genres in my own classroom-if I got so excited about it, I can see my future students acting in the same way. (Nanette - all names are pseudonyms)

This comment comes from a final reflection about a Multigenre Digital Inquiry Project (MDIP) and illustrates the effort put forth for this project. Have students ever told us that they are excited to wake up early on a Saturday to work on homework? The same homework that challenged them to be both creative and critical? As teacher educators, we strive for this kind of engagement.

With the increasing focus on the effectiveness of teacher education programs and additional requirements to include an array of courses in a program, such as technology, working with English learners, and differentiation (to name a few), it is imperative that teacher educators maximize time with students. In many cases, students have limited teaching methods courses, along with an array of other required courses in assessment, multicultural education, etc. To find ways to incorporate research, composing, and technology integration into our preservice teacher English Language Arts methods courses that would allow us to model highly effective teaching practices while students researched a topic of interest, we decided to study the incorporation of a MDIP in our courses. Our research questions were:

1. How do students choose to represent their learning from participating in a multigenre inquiry project?

2. How do students reflect on their learning from their participation in the project?

The MDIP requires students to research and report on a student-selected topic. Students share their research through 
writing in seven different genres that they publish on an original website. The project integrates inquiry and project-based learning with digital technology as two of the genres are created using digital tools. This is the digital world our students live in every day.

This article reports on our implementation of a MDIP into three different preservice teacher courses. We share themes and takeaways from a review of students' websites and end-of-semester reflections from our courses. We also provide lessons we learned in how to create an environment where students choose an inquiry topic and wrestle with how to present their learning in today's digital environment, how students learn about genres and what counts as text, and how personal interest leads to persistence in overcoming composing and technology challenges along the way.

\section{Theoretical Framework}

Two theories undergird our work with this project, (1) inquiry and learning and (2) teaching and learning with digital technologies.

\subsection{Inquiry and Learning}

The inquiry process focuses learning on a big question or big idea, either by groups of learners or by an individual (e.g., Burke, 2010; Wells, 1994; Wilhelm, 2007). Inquiry enables students to explore questions they have about real-world problems. Conducting inquiry as a class allows students to work together as a group of learners, learning with each other and sharing in the journey. As Boss and Larmer (2018) and MacKenzie (2016) point out, authentic topics, interesting questions, scaffolded instruction, opportunity to reflect, and sharing findings with people beyond the classroom are hallmarks of effective inquiry learning.

The inquiry projects we designed for this study engaged our students in exploring an individual self-chosen topic about teaching (the topic of our courses), provided instruction in research skills, scaffolded composing in different genres, and then asked students to interact with peers about their individual projects during the process. The final project was a website on the student's self-chosen inquiry topic that was shared with the class, although websites can be shared with a broad audience. Finally, our students were asked to reflect on what they learned and how they could use what they learned in the future. While, as MacKenzie (2016) says, inquiry learning can be an unsure and messy process, it empowers students to explore topics they are interested in and to share their learning in varied ways. Inquiry makes learning authentic and relevant to students' lives.

\subsection{Teaching and Learning with Digital Technologies}

New literacies, sometimes called multiliteracies or digital literacies, add a range of technologies to the traditional literacies of reading, writing, listening, and speaking to have students create and communicate using digital tools (New London Group, 1996; Hicks, 2013; Leu, Kinzer, Corio, Castek, \& Henry, 2019; Rybakova, et al., 2019; McGrail, et al., 2021). Using digital technology tools is an important component of teaching and learning for teachers and students alike. In keeping with the call that is found in the New London Group's "A Pedagogy of Multiliteracies" (1996), students would do well to gain experience using technology to create so they can support their own learning and development as teachers and eventually provide similar opportunities for their students. We learn by doing (Dewey, 1997). We also draw on Tyner's (1998) assertion that digital tools "collapse sight, sound, and motion" which then "accelerates experimentation" in multiple media (p. 39), which is increasingly prevalent in education.

In other words, teaching and learning with digital tools should not be limited to just consuming digital content but should include creating digital content and trying new digital tools. Our students need "[e]xperiences as digital writers and multimodal composers . . through coursework, specific assignments, and opportunities for reflection" (Pytash, Ferdig, \& Rasinski., 2013, p. 232). For example, Wickstrom (2013b) incorporated digital composing into her preservice teacher coursework using multigenre projects because "technology allows us to 'play' and explore, so any attempts are less permanent than pen and paper" (p. 24), although modeling and exploring technology resources together as a class were also considered important. The MDIP assignments researched for this project incorporated these key frameworks.

\section{Literature Review}

In this section, we review the literature on multigenre research projects and composing as a tool for learning. We then describe how previous literature on these topics influenced the design of our project. 


\subsection{Multigenre Research Projects}

Romano (1995) developed the idea of composing in multiple genres as a creative way for students to report on research. He defines multigenre papers as arising from "research, experience, and imagination ... composed of many genres and subgenres, each piece self-contained, making a point of its own, yet connected to other pieces by theme and content and sometimes by repeated language, images, and genres" (Romano, 2013, p. 8). A multigenre paper or project is an alternate way for students to share what they have learned doing research. Rather than writing a traditional academic research paper or literature review, students compose a paper or project written in many different genres to share their learning. For this project, genre is used as a broad term to identify purpose and format of a composition.

Other researchers have subsequently shown how composing multigenre inquiry papers or projects provide benefits for students of all ages. In some research on multigenre inquiry projects, students gained content knowledge as they worked on their projects in science (Rochwerger et al., 2006), social studies (West \& Saine, 2017), and pedagogy (Allen \& Swistak, 2004; Ciecierski, 2020; Rush, 2009). For example, Rush (2009) incorporated multigenre research projects in her English teacher education class and suggested that these projects enabled students to cross boundaries of different genres and connect theory to the practice of teaching the English language art.

Research often showed multiple benefits of the projects in addition to developing content knowledge, such as students building skills as readers and writers and building a reader/writer identity. For example, Allen and Swistak (2004) implemented several iterations of a multigenre project with pre-service teachers and elementary students and found that university students learned what it meant to be a writer and how important modeling the composing process was for students. Elementary students gained a sense of pride and accomplishment and became "confident presenters of research and writing" (p. 231). Sartor (2012/2013) showed how a multigenre research project engaged adults in an ESL reading class in critical and reflective thinking as they created multigenre books while also showing a significant increase in English proficiency. Rochwerger et al. (2006) reported how incorporating multigenre lab reports in science helped students develop their science knowledge and their composing skills in a group project.

Other research on multigenre projects showed the development of a community of learners through the project. For example, West and Saine (2017) incorporated a technology-mediated multigenre project where social studies teacher candidates mentored ninth grade students through a learning management system on the project. Ultimately, the research showed that the successful partnerships chose topics of high interest where the writers were invested in the topic and that pairing partners on topic was a key factor in the success of the project. Ciecierski (2020) noted that in a multigenre project during Covid-19 in her undergraduate teacher education class, choice was critical in broadening students' view of what writing is, as well as emphasized the value of the community of learners.

Of particular interest were the multigenre projects incorporated into teacher education courses (Allen \& Swistak, 2004; Ciercierski, 2020; Rush, 2009; West \& Saine, 2017). As an additional example, Wickstrom (2013a) described how she incorporated a technology-infused multigenre inquiry project with students and shared ways to incorporate the project in university courses. In her report on this project, Wickstrom (2013b) discussed five themes: 1) incorporating time during class for students to write provided opportunities for students to improve their own composing, 2) engaging in this project was a way to treat students like professionals who ask questions in order to improve their practice, 3) students required assistance across the inquiry process including the instructor providing resources or guidance towards resources, 4) inquiry provided opportunities for students to examine their own beliefs about teaching, and 5) transformative learning can be thoughtful and incremental, not necessarily dramatic. Ultimately, Wickstrom (2013a) determined that completing the project transformed students' thinking by giving them the opportunity to experience firsthand the process of completing an inquiry-based project through the use of highly effective teaching strategies that they could then take to their classrooms.

After considering the literature, we patterned this project after Romano's (1995; 2013) and Wickstrom's (2013a) work with some modifications. We considered how much class time to provide our students, what kinds of questions professionals ask about our content and how they would go about inquiring into their questions, how much assistance we would need to provide, and how students would reflect on the process. The project is described in detail in the Methodology section below.

\subsection{Writing as a Tool for Learning}

Research shows that writing can be an excellent tool for learning (Graham \& Perin, 2007), especially in the current multimodal learning landscape where writers produce texts in multiple modes such as visual, audio, or video in compositions (Kress, 2005: Prain \& Hand, 2016). Graham and Perin (2007) suggest setting goals for final products, 
using digital tools such as word processing as supports, prewriting as a way to generate or organize ideas, inquiry as a way to analyze data so students can gain knowledge for composing, a process writing approach including writing for real audiences, having students study examples of excellent writing as models, and using writing to learn across the content areas, among other things. Prain and Hand (2016), in their review of the research on learning through writing, focused on the research support for learning from composing with a particular eye to changes in technology and the inclusion of "multimodal and multimedia resources" to motivate learners (p. 430).

Thus, the MDIP project gave us a way to incorporate many of these strategies (Graham \& Perin, 2007) and multimodal learning opportunities (Prain \& Hand, 2016) into our preservice teacher classrooms. One opportunity in an inquiry-driven project such as this one is that students have the chance to choose a genre that "fits" the information they want to share. Typically, the use of multiple genres can provide students a chance to produce more "real world" writing, such as articles, letters, or brochures. We see billboards, tweets and other types of social media, and advertising in the real world. These are all options for the writer. This type of project also requires higher-order thinking skills, such as evaluating, synthesizing, and creating. Rather than composing an academic essay for the professor, the author of multiple genres must be able to think of the reader, what they (as the author) have determined is important information to share and make decisions on which genre would be best to share what they have learned from their inquiry. Composing using digital tools also gives students the chance to explore potential digital tools for their own use as well as tools they could use in their future classrooms. Students could produce a blog, a video, or a podcast. They could design a cartoon, a billboard, or an infographic. Students are only limited by what is available, what they are willing to try, and what might work for their topic.

We acknowledge that some teachers are familiar with multigenre projects and may already use them in their work. Our hope is that sharing the incorporation of digital pieces in our project may provide additional ideas for implementation in $21^{\text {st }}$ century classrooms. Ultimately, according to Romano (2013), the best way to help students understand the benefits of engaging in multigenre research projects, is to "make "em write one" (p. 230), so we did.

\section{Methods}

The purpose of this qualitative study (Merriam \& Tisdell, 2016) was to understand how pre-service teachers engage in a MDIP and reflect on their learning. Data collected included activities within the normal curriculum of each course. Here, we describe the three classroom settings, the details of the MDIP, the data collected, and our process of uncovering patterns across courses.

\subsection{Setting}

The classrooms we describe are in teacher education programs at two different universities. Marla and Amy teach at a statewide campus that is part of a large, public land-grant university and Jennifer teaches at a mid-sized, private university. A total of 33 students' work from across the three courses (those who gave consent) were included. Although all participants were students, the instructional focus of each class differed. Thus, we propose that teachers from other grade levels or content areas may find similar ways to incorporate the MDIP into their classrooms.

Marla's class was an elementary Language Arts methods class that focused on teaching writing and consisted of students who would be teaching elementary grades K-6. Marla taught this class in a synchronous broadcast format called Interactive Video Conferencing (IVC) with students across the state, meeting once weekly for the first 12 weeks of the semester. This course is usually taken one or two semesters before student teaching. She substituted the MDIP for an existing paper assignment that consisted of a report on a teacher interview, a mini lesson for teaching writing in an elementary grade, a letter to parents, and a graphic.

Amy's class was a writing methods course for students seeking to teach secondary English. Students traditionally take this course during their junior or senior year as part of the English Teaching track in the English department. Amy taught this class as a broadcast course that met over IVC once a week. She added the MDIP to the course.

Jennifer's class was a graduate literacy course and consisted of students who would be teaching either elementary or secondary grades. Although they were graduate students, the students were enrolled in graduate courses immediately after their undergraduate graduation and had not yet been employed as a teacher of record. This course was taught face-to-face, meeting once a week throughout the semester. Jennifer changed a research/inquiry assignment that had previously been assigned in this course and written as a literature review to the MDIP.

\subsection{The Multigenre Digital Inquiry Project}

Each instructor implemented a MDIP in their course. The basics of the project were based on multigenre writing 
projects (Romano, 2013) and modifications of a technology-infused multigenre project (Wickstrom, 2013b). To provide opportunities for learning in relevant, authentic, and personally meaningful ways, the students developed an inquiry question related to teaching the course content based on current curriculum standards and their knowledge and interests. Each course had slightly different guidelines depending on the content of the course.

Students then researched their inquiry question using classroom resources and searched for additional resources from teacher practitioner books or peer-reviewed journals on the topic with guidance from instructors. Students completed an annotated bibliography of their sources based on a what? So What? Now What? format (Patterson, Holladay, \& Eoyang, 2013; Wickstrom, 2013b). This is an open reading response inquiry format that helps students identify what is noteworthy in the reading (What?), why this information is important (So what?), and consider how they might use this information in answering their research question and in their future classroom (Now What?). Once students completed their research, they were ready to begin composing.

The MDIP assignment required students to create seven unique pieces of writing: one Dear Reader letter, one short essay (500-600 words), two substantive pieces, and three short pieces (Wickstrom, 2013b). We used Romano's (1995) definition of substantive piece versus short piece based on how much information was able to be shared in the piece of writing and provided students with a brainstormed list of genres as a starting place, slightly modified from Wickstrom (2013b). This list included which genres might work for substantive pieces or short pieces and how many were required to meet the criteria. Example genres for substantive pieces included infographics, magazine articles, song lyrics, and journal/diary entries. Shorter pieces included genres such as recipes, tweets (at least four), and bumper stickers (at least three). Students could also propose using different genres that were not on the list.

Table 1. Genres Used in the MDIP

\begin{tabular}{|c|c|c|}
\hline $\begin{array}{c}\text { Genres used by } \\
\text { more than } 10 \\
\text { students }\end{array}$ & Genres used by 3-9 students & Genres used by 1 or 2 students \\
\hline $\begin{array}{l}\text { Poem, word cloud, } \\
\text { word search, poster }\end{array}$ & $\begin{array}{l}\text { Infographic, menu, bumper } \\
\text { sticker, diary/journal entries, } \\
\text { flip book, comic strip, } \\
\text { tweets, crossword, quiz, } \\
\text { interview, billboard, recipe, } \\
\text { children's book, } \\
\text { letters/emails, blog/vlog }\end{array}$ & $\begin{array}{l}\text { Song lyrics, interest survey, dedication, slogans, } \\
\text { questionnaire, awards, book jacket, poll, resume, } \\
\text { tombstones, certificate, postcard, bingo, news headline, } \\
\text { character sketch, observation notes, magazine article, } \\
\text { brochure, lesson plan, job application, madlib, readers' } \\
\text { theater, fable, speech, timelines, newsletter, list, calendar, } \\
\text { video, game, review, anecdote, parody }\end{array}$ \\
\hline
\end{tabular}

Table 1 lists the wide variety of genres used in our students' projects. To provide digital composing opportunities for this project, at least two of the genres were to be written or created using technology, and the final project was to be shared on a student-created website (Wickstrom, 2013b). Also required was an element that tied the writing together, a memo explaining how each piece was made and how the piece fit within the inquiry topic, and a list of references in APA or MLA format (Romano, 2013, Wickstrom, 2013b). Students were provided with a model website and links to websites created by students in previous semesters to help them see what a finished product might look like. During the next few weeks, instructors discussed and/or modeled composing in different genres and shared technology tools that could potentially be used for the digital pieces (e.g., canva.com for infographics, flipsnack.com for digital books, weebly.com for websites). Students were also provided opportunities during class to discuss their projects with partners or small groups throughout the process.

\subsection{Data Sources}

For each course, in addition to crafting pieces of writing and incorporating them into a website, students were required to complete an end-of-semester reflection about their MDIP. The reflection questions used for this study asked students to identify and explain (a) their strongest piece of writing, (b) their weakest piece of writing, (c) composing in different genres and different digital media as a way of inquiring into their topic and communicating what they learned, (d) surprises about writing in different genres, and (e) what was helpful in creating their multigenre project. In addition to reflections, we particularly noted each Dear Reader letter and memos written about the different genres of the project, as these pieces of writing were more personal writing than genres designed to share information about what was learned from the inquiry. It is often in reflective writings such as these that student learning can be identified. Thus, the data sources analyzed for this project were the pieces of writing created by each 
student, the memos written by students about those pieces, and specific questions from the end-of-semester reflections.

\subsection{Data Analysis}

We began our analysis using descriptive statistics to capture the number of genres used and variance in chosen topics based on a review of each student website and followed the process in Figure 1.

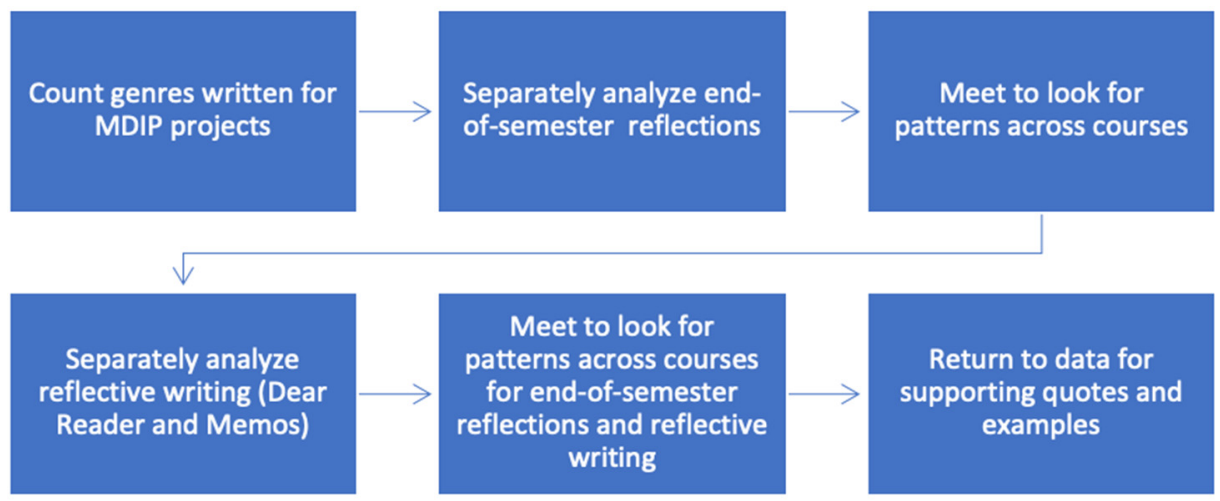

Figure 1. Data Analysis Process

Students chose a variety of topics such as how to work with English language learners, how to teach first graders to write, how to increase student engagement, and how to improve reading scores, to name a few. Our next step was conducting a qualitative analysis using the constant comparison method (Merriam \& Tisdell, 2016) looking for patterns in student answers to questions from the end-of-semester reflections (detailed above) that were relevant to this study to see how reflections answered our research questions. We used open-coding techniques (Merriam \& Tisdell, 2016) to allow common ideas to emerge into tentative categories and created a table with each question and a column for each of us to input the emerging codes from our individual analysis of our own courses. Subsequently we met together using the table for guidance and analyzed our codes for each question with the ultimate goal of determining categories that were common across the questions. For example, one of Marla's codes for the question about the strongest piece from the reflections was "contained the most/relevant/important information on a topic." One of Amy's codes was "that they felt best conveyed what they wanted to say." One of Jennifer's codes was "while also conveying the research on their topic." These codes were noted under the category "conveyed information that they wanted to share." We went through the same process for each question from the reflections and came up with between two and four common categories for each question.

For the next part of our analysis, we each reviewed the reflective writing pieces from the websites (Dear Reader Letters and student memos written about each written piece included in the website) from our own courses and looked for patterns in these to determine emerging categories. During this process, we added these to our table and went through the same process with these data, looking for commonalities. For example, in reviewing the codes from Marla from the memos, some of those codes were "broadens view of writing to include multiple modes, structures, etc. (their own writing)," and "how this piece takes a different spin on the same ideas presented in an essay . . . stretches the mind further." A few of Amy's codes for the memos were "creativity," "writing is more than focus on form and grammar," and "writing is expressing oneself - goes beyond standardized tests." Jennifer had a couple of similar codes: "discussed the visual/creative elements as part of their thinking process in choosing (13 total)," and "represent important information in a clear, concise way." We categorized these under "broader view of genre."

After completing that process, we then discussed any commonalities across the courses from both sets of categories and came to a consensus on themes across the data that were common across all three courses. We each went back to our data to verify our themes and found examples (e.g., quotes from reflections, written genres) we might use to represent each and discussed which one might be the best representation of the theme. The themes and takeaways reported below come from this analysis.

\section{Results and Discussion}

Here we report on our results as they relate to our research questions. We report the three major themes that emerged 
from the data analysis: (a) various methods of support are critical, (b) choice and inquiry lead to expansive views of writing, and (c) student reflections illustrate academic, personal, and pedagogical growth. Each of these themes are described below, are supported with quotes from students across the three courses, and include example genres written for the project, when appropriate.

\subsection{Various Methods of Support are Critical}

The amount of guidance I received in creating my multigenre project was the most helpful. We received ample examples, class time and directions to be successful on this project. (Susan)

Some patterns we found were similar to previous research on writing instruction (Graham \& Perin, 2007). For example, our data showed students valued support throughout the project, such as the structured design of the MDIP that included specific guidelines (genre sheet, annotated bibliographies), a rubric, and timelines (planning guide). Students also appreciated studying exemplars (an example website and previous student's websites), instructor modeling of technology tools, and scaffolded writing such as collaborative writing opportunities during class using genre choices for the project.

Another aspect of support that students appreciated was the opportunity for collaboration, also highlighted in previous research (Graham \& Perin, 2007). All three of us provided time across the project for our students to work with us and with writing partners or in writing groups as they researched their topic and drafted writing for their project. One student commented that it was helpful to "talk to someone about problems I came across, frustrations I had, share new things I had learned, or get a second opinion on things." This aspect of collaboration seemed to benefit our students.

Romano (2013) mentions that "multigenre anxiety" (p. 46) can be an issue when students are attempting to write in new and unfamiliar genres, especially if they had been previously successful in composing traditional academic papers. In our MDIP, incorporating new digital writing tools may have compounded that anxiety for those unfamiliar with using these multimodal tools. However, many students reported that our guidance and structure, including with technology, seemed to mitigate some of this anxiety.

\subsection{Choice and Inquiry Lead to Expansive Views of Writing}

Different genres take on different perspectives and ways of thinking that involve deeper understanding of the topics and allow you to look at the ideas in new ways. (Marianne)

One of the noted benefits of allowing students choice is the variety of topics and genres chosen. Among our 33 participating students, 26 different topics related to teaching were chosen. Multiple students chose to inquire about teaching writing (the topic of two of the courses) with English language learners, guided reading (although one was on bilingual guided reading), writing creatively, writing with technology, writing in science, and differentiation (although one focused on elementary and one focused on high school). Other topics ranged from motivation to early literacy, daily writing, spelling, math, and using fantasy. Even the students who chose similar topics asked different inquiry questions, and their final projects were unique.

\subsubsection{Broader View of Genre}

Our students wrote in 52 different genres for the MDIP project. Some of these were for substantive pieces and others were for short pieces. See Figure 2 for an example of an infographic (created with canva.com), a genre that students realized was a way to convey academic content. 


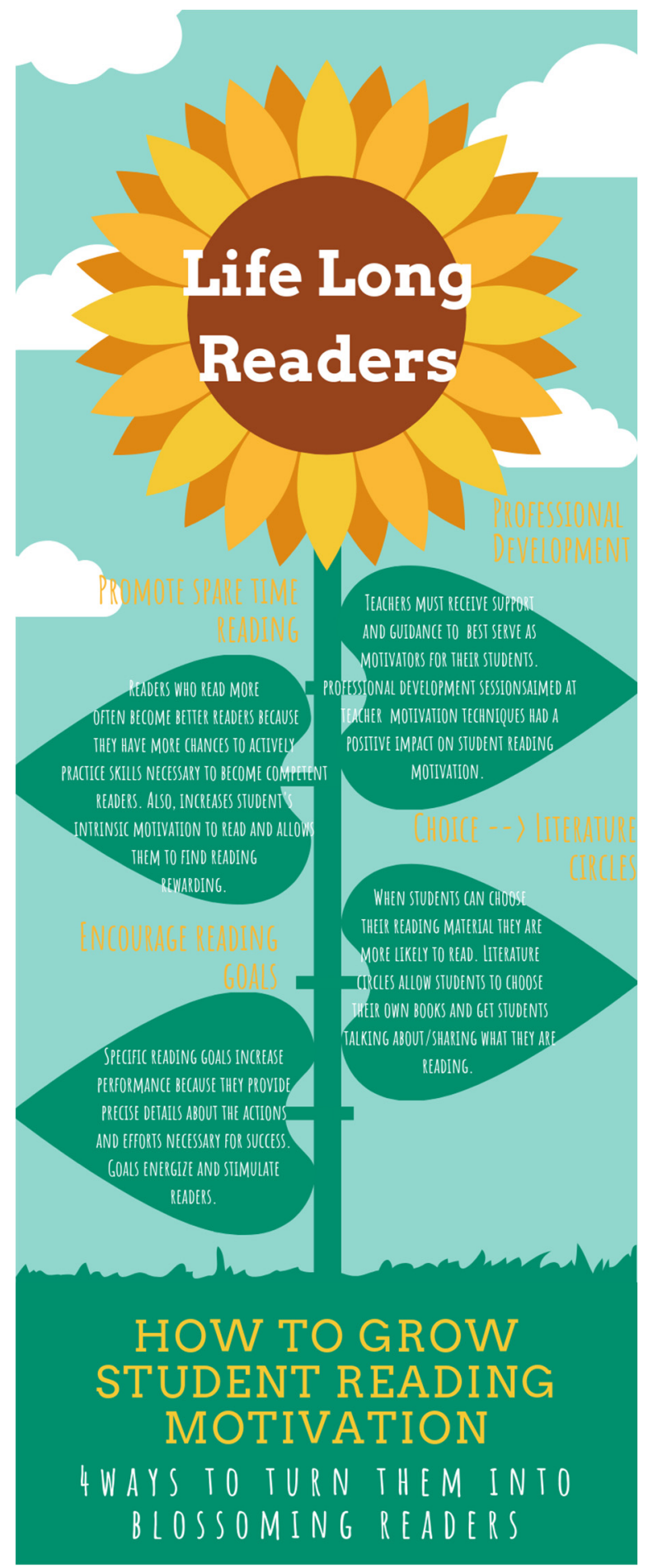

Figure 2. Genre Example: Infographic for the Inquiry Topic of Motivation

Figure 3 shows another example, a song parody of John Lennon's "Imagine," and also includes the student-written memo explaining why the genre was chosen and how it fit with the inquiry topic. The multimodal components of this project also allowed the student to embed a link to the background music so the reader could listen or sing along. In fact, in her presentation, she and another member of the class sang along to the music. 


\author{
Imagine \\ Imagine children writing. It's easy if you try. \\ Picture books before us. Lunch clubs for small fry. \\ Imagine first grade students \\ Writing every day. \\ $\mathrm{Ah}$, \\ Imagine journal writing. It isn't hard to do. \\ Give consistent feedback, sharing chances too. \\ Imagine all your students, writing with confidence. \\ You
}

You may say I'm a teacher. But I'm not the only one,

I hope you'll do shared writing. Your students will have so much fun.

Imagine buddy edits. I wonder if you can.

You'll need to have them role-play, and teach them not to pan.

Imagine all the children writing to the world.

You

You may say I'm a teacher. But I'm not the only one,

I hope you'll play some music, to set the mood for everyone.

Memo: I wrote this parody of John Lennon's "Imagine" because before I did my research, I was having a hard time imagining what I could do with first graders in the writing department. Now I found the answers that I couldn't "Imagine." Teachers getting ideas from other teachers helps us all go beyond our own imagination and see different ways of doing things. The instrumental is provided if you wish to sing along! https://youtu.be/zl49tDPMZ1U (included this embedded in the website)

Figure 3. Genre and Memo Example: Song Parody for the Inquiry Topic of Writing in First Grade

In reference to genre, students mentioned making choices about a particular genre that matched the purpose of the text or the information being shared. One student reflected,

When this project was first presented to me, I thought it would be easy to come up with all the different genres and they would be quicker to make than writing a traditional literature review. I quickly realized that genre selection had to be precise and sometimes involved trying multiple before deciding on the final.

In one memo, a student explained why she chose a comic strip to represent part of her learning, noting that it was the best way "to demonstrate a very important aspect of incorporating English language learners into classroom writing instruction." Having a wide variety of genres to choose from encouraged a broader use of genres in our students' writing.

\title{
5.2.2 Expanded View of Ways to Communicate Research
}

Several students also mentioned that their inquiry and composing for this project expanded their view of what counts as text. For example, one student reflected on her newfound realization of the many different ways she could communicate her ideas: "Different genres take on different perspectives and ways of thinking that involve deeper understanding of the topics and allow you to look at the ideas in new ways."

In a memo about an $\mathrm{ABC}$ poem included in a project about the importance of writing daily, a student reflected, "this piece, in the form of a long free verse poem, takes a different spin on the same ideas presented in the essay. This piece stretches the mind further though, because of the need for each letter of the alphabet to be filled with something relating to the topic." Another student noted that she did not have much background knowledge on some genres but decided to challenge herself to try something new. See Figure 4 for this student's example of personifying "data" and "observation," which we called a character sketch. These were modeled after J. Ruth Gendler's writing in The Book of Qualities (1984). By experimenting with models of others' writing and trying new things in their own writing, students saw many new ways to communicate. 


\section{Data}

Data is powerful. He is trustworthy and can help teachers drive their instruction. He is able to represent students ability to problem-solve, read with automaticity, and receive an understanding of their comprehension skills. He likes to be consistent and effective. I never create a lesson without him in mind. He does not like to be forgotten. He can be represented in many forms|such as observation notes, running-records, and smallgroup discussions. He likes to help teachers make effective decisions in order to help all students be confident and life-long readers.

\section{Observation}

Observation is the key to a powerful guided-reading lesson. She likes to see how individuals complete word work, decode, and problem-solve throughout the story. She never stops working. She is available to observe for any-type of text or genre. She encourages me to give student's wait time before stepping in for assistance. She has endless amounts of knowledge of different reading strategies and skills. She asks educators to help students implement effective reading strategies when she sees they are stuck. She wants the best for students and will always be there to see what they need.

Figure 4. Genre Example: Character Sketch for the Inquiry Topic of Guided Reading

\subsection{Student Reflections Illustrate Academic, Personal, and Pedagogical Growth}

I really enjoyed doing this project. My favorite part of it was making the cartoon. I really enjoy artistic activities, so being able to incorporate a creative and artsy activity was really fun for me. I also learned that while every genre was different, they ALL communicated important parts of what I was writing about. I don't need to write an essay to communicate an idea. I can write in any way and be effective. (Rhonda)

The final theme we found across our courses was that working on the MDIP was an overall positive experience for students, based on the coding of student reflections and memos. In university coursework, the primary goal is for students to learn the content of the class, typically an intellectual or academic goal. There is, however, an affective dimension of teaching and learning as well.

\subsubsection{Tapping into Personal Interest}

Many students referenced their personal interest in this project, and we found this interest was a combination of academic, personal, or pedagogical elements. This was especially noted in Dear Reader letters, where students often cited personal reasons for their interest in their chosen topic with phrases such as "I am a strong believer in...," "I believe that is important to...," or "I felt very disconnected and bored...Did you, or do you, ever feel this way?" as ways to explain why they chose their topic for their MDIP. This was followed by phrases such as "That is why...," "I hope that this website will inspire you to think outside of the box when it comes to...," or "I hope you will find the work I have done helpful..." These quotes illustrate students' personal interest in their inquiry topic (MacKenzie, 2016), newfound academic knowledge, and pedagogical growth.

\subsubsection{Challenging yet Rewarding}

In addition to comments about gaining knowledge, students reflected on their experiences throughout the process. For example, students talked about how much fun they had, how easy or hard the composing was, how they enjoyed creating a particular piece, or how the project challenged them. Some students felt composing with technology was "hard," or "difficult but fun", but also noted that the tool was something they would "use in the future."

Often students identified their strongest piece as the one that meant the most to them or was the most personally fulfilling. One student noted that her bedtime story presented in digital book format was her strongest piece of writing, "not because it's the best piece of writing, but because I spent the most time on it, learned the most from it, and enjoyed it the most. It reminded me how much I love to write." A student in a different class cited her digitally designed infographic as her strongest piece, "because it represents my comprehension of the material and ability to synthesize the information." Another student composed tweets and reflected on the creative process:

I had to think really critically about what information I wanted to include since the character count is so low on tweets. I wanted the tweets to be from students, so I knew that they needed to have some sort of conveying of 
feelings, but I also wanted them to point to particular strategies for specific types of readers. Because I wanted both of these to be in the tweets, I was very intentional with crafting each one. (See Figure 5 for tweets)

This quote illustrates what we saw throughout many of the responses - that students' strongest pieces were challenging and creative, while successfully conveying the intended information, and displayed a high level of thinking.

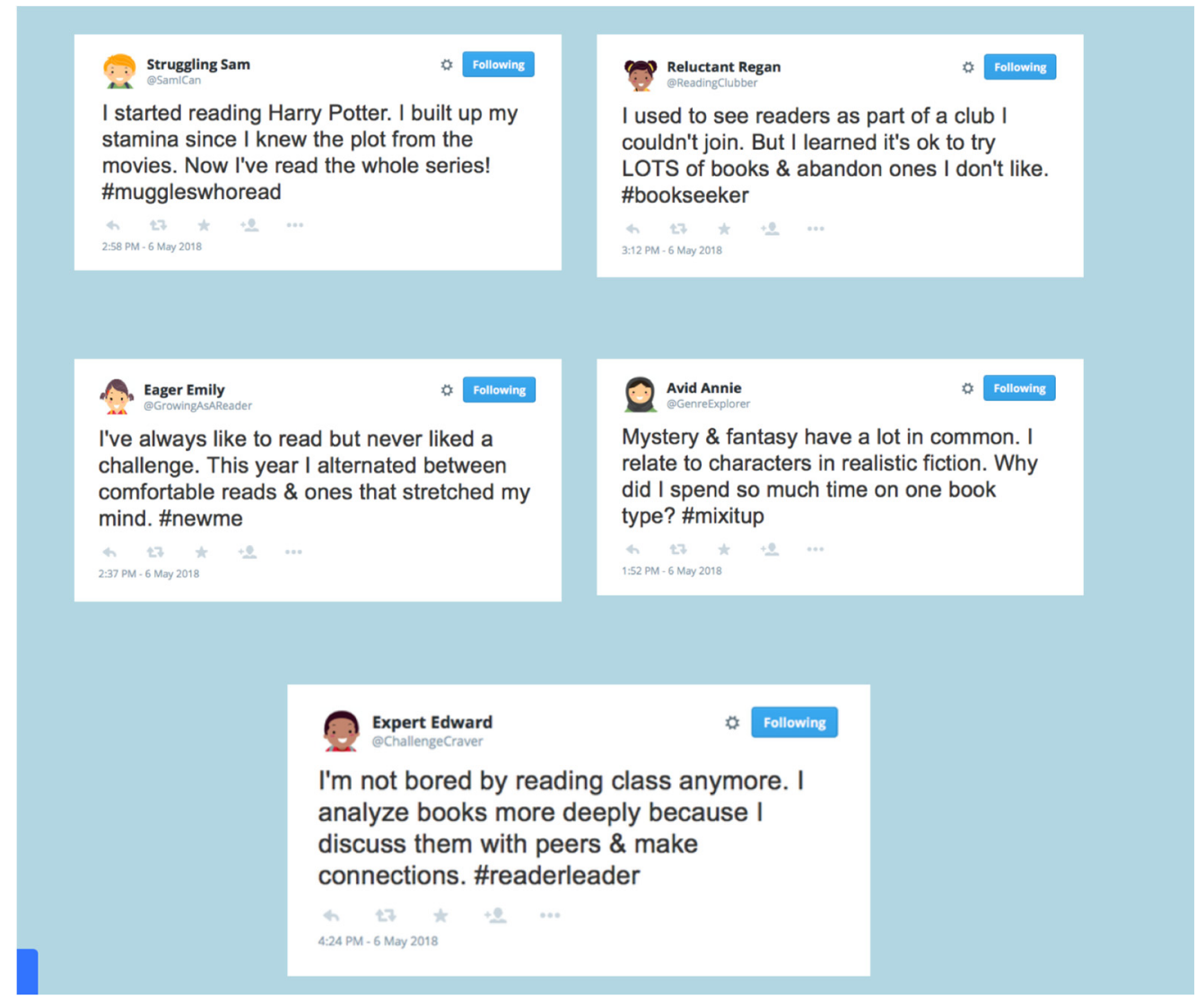

Figure 5. Genre Example: Tweets for the Inquiry Topic of Reading Workshop

Although many students mentioned the project was challenging as a whole, requiring them to make multiple decisions and explore digital tools and genres they might be unfamiliar with, they also included how proud they were of their work and how enjoyable this project was. One student stated she was surprised "that I could actually do it" and another talked about how learning to create a website "was really empowering for me." A student who had grown weary of traditional writing assignments shared, "Creating different genres for this project was actually a lot of fun. During school, it is easy to become tired of writing paper after paper. Having the opportunity to be creative for once was such a breath of fresh air for me."

\subsubsection{Sharing Learning}

Many students used affective terms in sharing their website with others, despite what they considered to be difficult along the way. This was typically noted in Dear Reader letters. Phrases such as "I hope you feel as excited as I do" or "I have provided some ideas of my own, but I am just beginning this adventure" or "I feel much more confident" were often a part of the letter. Some students even cited the Dear Reader letter as their strongest piece.

The experiences students had completing the MDIP and the course they took seemed to impact their approach to teaching, which is the goal of our courses. One student remarked, "I have learned that writing is not just some separate, sterile thing. It crosses into art, reading, speaking, science, etc." This comment suggests that this student saw writing as enabling human expression of thoughts and emotions rather than a formulaic task to complete. We feel that teachers would do well to cultivate this same sense of writing in the classroom in order to be effective and 
confident teachers. In fact, many of Marla's and Amy's students said at the end of the course that they felt more confident in their ability to teach writing (the purpose of the course) than they did at the beginning of the course. Likewise, Jennifer's students stated that they planned to use aspects of the project in their future classroom, including the integration of different genres and types of digital technology.

\section{Conclusion}

After taking on this project, we have several ideas for changes we plan to make in future iterations. We found that this project was successful in getting students to research topics of interest related to the course and to present their learning digitally in multiple genres, but we want to continue to improve our design and teaching of this project in future semesters.

1) We intend to add a curated piece to project requirements. A curated piece is a piece the student finds online rather than creating the piece themselves. This could be a video of a TED Talk, a blog post, or a podcast episode that addresses the topic being researched. Curation has been recognized as a vital digital literacy skill (Sharma and Deschaine, 2016).

2) There is a learning curve in designing a website if one has not done it before. Time to model how to use Weebly or another tool to create a website can be helpful, as can providing time during class for students to work on their website with their peers and teacher present for support.

3) Many students noted that the shorter genres were difficult to craft because they were limited in the content they could present in a shorter piece. Therefore, it's important to talk with students about concision and how to make the most of shorter pieces. We also plan to cut some of the shorter genres from the genre list like the word search, crossword, and word cloud as students found them to be too easy to make and felt they did not contribute to the project as well as other genres.

4) We may reduce the number of required pieces while keeping the essay and the Dear Reader Letter. This project does lend itself to being smaller or bigger depending on course goals and other activities that must get done during a course.

5) All students used digital tools, but most did not take advantage of the multimodal capabilities such as audio and video available to them in presenting their work on a website. For example, the ability to create movies, podcasts, and other multimodal options is one of the differences between composing a multigenre paper and designing a multigenre website. More students may incorporate sound and video within their projects if they are provided a variety of examples.

The MDIP that was implemented in our three courses served many purposes: (a) it allowed students the space to research a topic about teaching that was important to them, (b) it provided opportunities for us to model pedagogical practices that we hope to pass onto our students, (c) it challenged students to think both academically and creatively, (d) it provided opportunities for composing in digital environments, and (e) though it was a lot of work, it was a valued learning experience for the students. Incorporating this project also provided the three of us the opportunity to inquire and collaborate on our own course design, pedagogy, and use of technology.

This research highlighted several pedagogical practices that were instrumental to the success of the MDIP. First, inquiry (Boss \& Larmer, 2018; MacKenzie, 2016) can be a powerful tool for learning. The students in our classes chose to research a topic that they were interested in and would make a difference in their future. Many students reflected on how they might use the learning from this project in their classrooms, not only the learning on their topic but inquiry into digital technologies, making this required assignment relevant to each of them in our context.

Second, students were given choice with structure and ongoing support (Graham \& Perin, 2007; Wickstrom, 2013b). The variety of digital technology tools students chose to use and the pieces they created with these tools are consistent with prior work emphasizing the need to experiment (Tyner, 1998) and the need for students to create rather than simply consume digital media (New London Group, 1996; Hicks, 2013). Students had a choice of topic, genres, and technology tools. While choice was important, the structure kept students accountable and made our expectations clear. The students were deeply engaged in a topic that was important to them, found genres and technology tools that were appropriate to convey the information, and knew what they needed to do to succeed. Support was provided through detailed directions and rubrics, examples of genres and websites, modeling by the instructors, collaboration with peers, and a timeline that staggered due dates for the pieces of the project (Graham \& Perin, 2007). The rigor and enormity of the MDIP was balanced by the choices and support provided. 
Finally, there is no substitute for practical experience. It was through this assignment that our students learned the difficulty of finding a genre to fit the purpose of the writing but simultaneously reconceptualized the definition of genre and expanded their view of writing as a way to share what they have learned. The technology tools that were daunting at the beginning of the project were used successfully, and students began envisioning how they might use these same tools in their future classrooms (Knobel \& Lankshear, 2014; Pytash et al., 2013). By working collaboratively to practice using technologies, composing genres, and sharing ideas, students realized the importance of providing support in multiple contexts. We recommend reflecting on the assignments in your class that require research or inquiry. Are there any that could be adapted into a multigenre digital inquiry project? Also, consider making a MDIP of your own to understand the process and to have an example for your students.

In short, by assigning the MDIP, we were able to do more than just have students research and write about a topic. They also learned that writing is a tool for learning in our digital world (Graham \& Perin, 2007; Hicks, 2013; McGrail, et al., 2021) and the ability to write using multimodal elements is a part of that learning (Prain \& Hand, 2016). They stretched themselves, surprised themselves, and learned practices to implement in their future classrooms. The thoughtful and flexible design of the MDIP gave students the platform, space, support, and opportunity to inquire, create, and expand their knowledge, while also expanding their pedagogical toolbox, in challenging, yet rewarding ways.

Acknowledgements: This work was supported in part by the Utah State University New Faculty Success in Scholarship Grant.

\section{References}

Allen, C. A., \& Swistak, L. (2004). Multigenre research: The power of choice and interpretation. Language Arts, 81(3), 223-232.

Boss, S., \& Larmer, J. (2018). Project based teaching: How to create rigorous and engaging learning experiences. Alexandria, VA: ASCD.

Burke, J. (2010). What's the big idea? Question-driven units to motivate reading, writing, and thinking. Portsmouth, NH: Heinemann.

Ciecierski, L. (2020). The sunshine between the clouds: Lessons learned and remembered during COVID-19 through multigenre writing. Ohio Journal of English Language Arts, Summer/Fall(1), 42-43.

Dewey, J. (1997). Experience and education. New York, NY: Touchstone.

Gendler, J. R. (1984). The book of qualities. Berkeley, CA: Turquoise Mountain Publications.

Graham, S., \& Perin, D. (2007). Writing next: Effective strategies to improve writing of adolescents in middle and high schools-A report to Carnegie Corporation of New York. New York: NY: Alliance for Excellent Education.

Hicks, T. (2013). Crafting digital writing: Composing texts across media and genres. Portsmouth, NH: Heinemann.

Knobel, M., \& Lankshear, C. (2014). Studying new literacies. Journal of Adolescent \& Adult Literacy, 58(2), 97-101. https://doi.org/10.1002/jaal.314

Leu, D., Kinzer, C., Corio, J., Castek, J., \& Kenry, L. (2019). A dual-level theory of the changing nature of literacy, instruction, and assessment. In D. Alvermann, N. Unrau, M. Sailors, and R. Ruddell (Eds.), Theoretical Models and Processes of Literacy (7th ed.) (pp. 319-346). Routledge.

MacKenzie, T. (2016). Dive into inquiry: Amplify learning and empower student voice. Del Mar, CA: Elevate Books Edu.

McGrail, E., Turner, K. H., Piotrowski, A., Caprino, K., Zucker, L., \& Greenwood, M. E. (2021). An interconnected framework for assessment of digital multimodal composition. English Education, 53(4), 277-302.

Merriam, S. B., \& Tisdell, E. J. (2016). Qualitative research: A guide to design and implementation. San Francisco, CA: Jossey-Bass.

New London Group. (1996). A pedagogy of multiliteracies: Designing social futures. Harvard Educational Review, 66(1), 60-92. https://doi.org/10.17763/haer.66.1.17370n67v22j160u

Patterson, L., Holladay, R., \& Eoyang, G. (2013). Radical rules for schools: Adaptive action for complex change. 
Circle Pines, MN: Human Systems Dynamics Institute.

Prain, V., \& Hand, B. (2016). Coming to know more through and from writing. Educational Researcher, 45(7), 430-434. https://doi.org/10.3102/0013189X16672642

Pytash, K. E., Ferdig, R. E., \& Rasinski, T. V. (2013). Assessing the impact of technology on preparing teachers to write using technology. In Still, K., Fertig, R., \& Rasinski, T. (Eds.), Preparing Teachers to Teach Writing Using Technology (pp. 227-248). Retrieved from https://www.nwcbooks.com/download/preparing-teachers-to-teach-writing-using-technology/

Rochwerger, L., Peterson, S. S., \& Calovini, T. (2006). Multigenre lab reports: Connecting literacy and science. Science Scope, 27(7), 26-29.

Romano, T. (1995). Writing with passion: Life stories, multiple genres. Portsmouth, NH: Heinemann.

Romano, T. (2013). Fearless writing: Multigenre to motivate and inspire. Portsmouth, NH: Heinemann.

Rybakova, K., Rice, M., Moran, C., Zucker, L., McDermott, M., McGrail, E., Loomis, S., Piotrowski, A., Garcia, M., R. Gerber, H., Marlatt, R., \& Gibbons, T. (2019). A long arc bending toward equity: Tracing almost 20 years of ELA teaching with technology. Contemporary Issues in Technology and Teacher Education, 19(4), 549-604.

Rush, L. S. (2009). Developing a story of theory and practice: Multigenre writing in English teacher education. The Teacher Educator, 44, 204-216. https://doi.org/10.1080/08878730902960735

Sartor, V., \& Hill, B. (2012/2013). ESL student identity and the multigenre research project. The CATESOL Journal, 24(1), 305-315.

Sharma, S. A., \& Deschaine, M. E. (2016). Digital curation: A framework to enhance adolescent and adult literacy initiatives. Journal of Adolescent \& Adult Literacy, 60(1), 71-78. https://doi.org/10.1002/jaal.523

Simon, L. (2007). Expanding literacies: Teachers' inquiry research and multigenre texts. English Education, 39(2), 146-176.

Tyner, K. (1998). Literacy in a digital world: Teaching and learning in the age of information. New York, NY: Lawrence Erlbaum Associates.

Wells, G. (1994). Changing schools from within: Creating communities of inquiry. Portsmouth, NH: Heinemann.

West, J.A., \& Saine, P. (2017). The mentored multigenre project: Fostering authentic writing interactions between high school writers and teacher candidates. Journal of Adolescent and Adult Literacy, 60(6), 629-641. https://doi.org/10.1002/jaal.602

Wickstrom, C. D. (2013a). Inquiry can be transformative: From "I will make him write" to "He will learn to write". In S. Szabo, L. Martin, T. Morrison, L. Hass, and L Garza-Garcia (Eds.), Literacy is Transformative: The Thirty-Fifth Yearbook of the Association of Literacy Educators and Researchers (pp. 255-273). Retrieved from https://c.ymcdn.com/sites/www.aleronline.org/resource/resmgr/yearbooks/yearbook_volume_35.pdf

Wickstrom, C. D. (2013b). Developing students for 21st century teaching: Inquiry, the multigenre research paper, and technology. In Still, K., Fertig, R., \& Rasinski, T. (Eds.), Preparing Teachers to Teach Writing Using Technology (pp.

17-42). https://www.nwcbooks.com/download/preparing-teachers-to-teach-writing-using-technology/

Wilhelm, J. (2007). Engaging readers and writers with inquiry. New York, NY: Scholastic Teaching Resources.

\section{Copyrights}

Copyright for this article is retained by the author(s), with first publication rights granted to the journal.

This is an open-access article distributed under the terms and conditions of the Creative Commons Attribution license (http://creativecommons.org/licenses/by/4.0/). 